\title{
Isopulegol Ameliorates Dyslipidemia by Modulating Adipokine Secretion in High Fat Diet / Streptozotocin Induced Diabetic Rats
}

\author{
Kalaivani Karunanithi, Sankaranarayanan Chandrasekaran * \\ Department of Biochemistry and Biotechnology, Annamalai University, Annamalainagar- 608002, Tamilnadu, India.
}

\begin{abstract}
The present study investigates the effect of isopulegol on adipokine secretion and dyslipidemia in high fat diet and streptozotocin (HFD/STZ) induced diabetic rats. Animals were made diabetic by feeding HFD for 4 wks followed by single intraperitoneal injection of STZ (35mg/kg b.w; $0.1 \mathrm{M}$ citrate buffer; $\mathrm{pH} 4.0$ ). Diabetic rats showed increased levels of total cholesterol, triglycerides, free fatty acids, phospholipids, low density lipoprotein-C (LDL-C), very low density lipoprotein -C (VLDL-C) and decreased high density lipoprotein-C levels (HDL-C). Similarly, the activity of HMG-CoA reductase, was increased while lipoprotein lipase (LPL) and lecithin cholesterol acyl transferase (LCAT) activities were significantly decreased. Furthermore, the expression of sterol regulatory element binding protein-1C (SREBP-1C), adiponectin, peroxisome proliferator activated receptor gamma (PPAR $\gamma$ ) were significantly down regulated, whereas leptin expression was upregulated in diabetic rats. Administration of isopulegol (100 mg/kg b.w) for 28 days significantly restored lipid levels in plasma and liver tissue by modulating adipokine secretion in diabetic treated rats. From this we conclude that isopulegol exhibited significant antihyperlipidemic effect in HFD/STZ induced diabetic rats.
\end{abstract}

Keywords: Dyslipidemia, Diabetes mellitus, Adiponectin, Leptin, PPAR $\gamma$, SREBP-1C

Article Info: Received 13 July 2019; $\quad$ Review Completed 17 August 2019; $\quad$ Accepted 24 August 2019; Available online 30 Aug 2019

Cite this article as:

Kalaivani K, Sankaranarayanan C, Isopulegol Ameliorates Dyslipidemia by Modulating Adipokine Secretion in High Fat Diet / Streptozotocin Induced Diabetic Rats, Journal of Drug Delivery and Therapeutics. 2019; 9(4-A):126-136 http://dx.doi.org/10.22270/jddt.v9i4-A.3429

*Address for Correspondence:

Chandrasekaran Sankaranarayanan, Department of Biochemistry and Biotechnology, Annamalai University, Annamalainagar- 608 002,

Tamilnadu, India

\section{INTRODUCTION}

Diabetic dyslipidemia in type 2 diabetes mellitus is characterised by a cluster of lipid and lipoprotein abnormalities which is an important risk factor for coronary artery disease and stroke. High fat diet and oxidative damage contributes to the development of dyslipidemia and impairs insulin signaling in diabetes mellitus [1]. Lack of responsiveness and an inability to control hyperlipidaemia are the drawbacks associated with the long term use of the currently available antidiabetic drugs Controlling dyslipidemia is of prime importance in preventing cardiovascular risk in diabetes mellitus. The rationale use of phytochemicals offers hope for a more effective drug in the management of diabetes mellitus.

Isopulegol a naturally occurring monoterpene is widely distributed in grape fruit, mint, rosemary oil and possess numerous pharmacological properties [2]. Recently, we reported that isopulegol regulated the activities of carbohydrate metabolic enzymes and improved insulin secretion in high fat diet (HFD)/streptozotocin (STZ) induced diabetic rats [3] . In this context the present study was designed to investigate the potential role of isopulegol on dyslipidemia, and on adipokine levels in HFD/STZ induced diabetic rats

\section{MATERIALS AND METHODS:}

\subsection{Chemicals and drugs}

Isopulegol and STZ were purchased from Sigma Aldrich Pvt. Ltd., (St.Louis, MO,USA). Diagnostic kits for cholesterol and triglycerides were purchased from Agappe diagnostics Ltd, Kerala, India. All other chemicals used in this study were of analytical grade and obtained from SD fine and HIMEDIA, India.

\subsection{Ethical statement for animal experimentation}

Thirty adult male wistar rats with body weight ranging from 180 to $200 \mathrm{~g}$ were purchased from National Centre for Laboratory Animal Science, Bangalore. They were housed in well-ventilated cages (temperature $23 \pm 2{ }^{\circ} \mathrm{C}$, humidity 65 $70 \%$ and $12 \mathrm{~h} \mathrm{light/dark} \mathrm{cycle),} \mathrm{fed} \mathrm{on} \mathrm{pellet} \mathrm{diet} \mathrm{and} \mathrm{water}$ ad libitum. Studies were carried out in accordance with 
Indian National Law on Animal Care and Use and were approved by the Institutional ethical committee (Proposal No.1000) of Rajah Muthiah Medical College and Hospital, Annamalai University, India.

\subsection{Development of type 2 diabetes mellitus}

Rats divided into five groups with six in each group were placed under normal pellet diet and water for a week prior to dietary manipulation. Experimental animals in three groups were fed with a HFD (40\%) for 4 weeks. This was followed by a single intraperitoneal injection of freshly prepared STZ (35 mg/kg b.w) dissolved in $0.1 \mathrm{M}$ citrate buffer ( $\mathrm{pH} 4.5$ ). After one week, fasting blood glucose levels were determined and rats with glucose levels $>250 \mathrm{mg} / \mathrm{dl}$ were considered as diabetic and used in this study.

\subsection{Experimental design}

Animals were grouped and treated as follows.

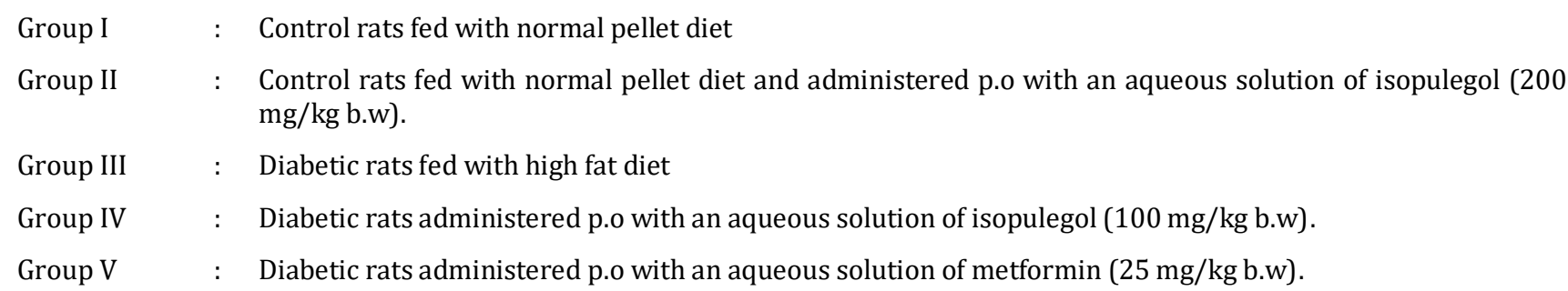

\subsection{Extraction and assay of lipids}

Lipid extraction from tissues were carried out by the method of Folch et al [4]. By adopting suitable methods the levels of TC [5], HDL-C [6], LDL-C \& VLDL-C [7], TG [8], FFA [9], PL $[10]$, LPL and LCAT activity $[11,12]$ were measured.

\subsection{Western blotting analysis}

The expression pattern of adiponectin and leptin were analysed in the adipose tissue [13]

\subsection{Histological examination}

Haematoxylin and eosin staining of adipose tissue was performed as described by Hine [14].

\subsection{Quantitative real time -PCR (q RT-PCR)}

Total RNA was extracted using TRIzol reagent (Invitrogen Bioservices India Pvt. Ltd) according to the manufacturer's instructions. The reverse transcription reaction was conducted using miScript Reverse Transcription Kit (Genei, India). Real-time PCR was conducted on the PCR System with SYBR Premix Ex Taq (Bangalore, India)

\section{The primers sequences used are as follows:}

\begin{tabular}{|c|c|c|}
\hline Gene & Accession number & Primer \\
\hline \multirow[t]{2}{*}{ PPAR $\gamma$} & 088275 & F : 5' GGAATGGGAGTGGTCATCCA3' \\
\hline & & R : 5' CCCACCAACTTCGGAATC3' \\
\hline \multirow[t]{2}{*}{ SREBP-1C } & P56720 & F : 5' GCTCAGGGTGCCAGCGAACCAGTG3' \\
\hline & & R : 5' GGGTTACTAGCGGACGTCCGCC3' \\
\hline GAPDH & P04797 & $\begin{array}{l}\text { F: 5' AAGGGGAACCCTTGATATGG 3' } \\
\text { R: 5' GGGAGATGATGATGACCCTTTT 3' }\end{array}$ \\
\hline
\end{tabular}

\subsection{Statistical analysis}

All data were expressed as mean \pm S.D of number of experiments $(n=5)$. The statistical significance was evaluated by one-way analysis of variance (ANOVA) using SPSS version 20 (SPSS, Cary, NC, USA) and the individual comparison were obtained by Duncan's multiple range test (DMRT).

\section{RESULTS}

\subsection{Influence of isopulegol on circulating lipids}

Table1 shows the levels of TC, TGs, PLs, FFAs in plasma of control and experimental rats. Diabetic rats showed significantly elevated levels of TC, TGs, FFAs and PLs levels when compared with normal rats. Oral administration of isopulegol $(100 \mathrm{mg} / \mathrm{kg}$ b.w) for 28 days to diabetic rats significantly reduced the levels of above lipids when compared to diabetic rats. These findings are comparable with metformin treated diabetic rats. 
Table 1: Effect of isopulegol on the levels of TC, TGs, FFAs and PLs in the plasma of normal and experimental rats

\begin{tabular}{|c|c|c|c|c|}
\hline Groups & TC (mg/dl) & TGs (mg/dl) & FFAs (mg/dl) & PLs (mg/dl) \\
\hline Normal & $95.21 \pm 7.25^{\mathrm{a}}$ & $80.61 \pm 6.13^{a}$ & $63.31 \pm 4.82^{\mathrm{a}}$ & $85.21 \pm 6.49 a$ \\
\hline $\begin{array}{l}\text { Normal+isopulegol }(200 \mathrm{mg} / \mathrm{kg} \\
\text { b.w) }\end{array}$ & $96.04 \pm 7.35^{\mathrm{a}}$ & $85.24 \pm 6.52 \mathrm{a}$ & $62.03 \pm 4.74 \mathrm{a}$ & $76.34 \pm 5.84 \mathrm{a}$ \\
\hline Diabetic (HFD/STZ) & $167.28 \pm 12.80^{b}$ & $154.37 \pm 11.81^{b}$ & $130.16 \pm 9.96^{b}$ & $150.27 \pm 11.50^{b}$ \\
\hline $\begin{array}{l}\text { Diabetic+isopulegol }(100 \mathrm{mg} / \mathrm{kg} \\
\text { b.w) }\end{array}$ & $120.36 \pm 9.21^{c}$ & $110.25 \pm 8.44^{c}$ & $80.64 \pm 6.17 c$ & $108.25 \pm 8.28^{c}$ \\
\hline $\begin{array}{l}\text { Diabetic + metformin }(25 \\
\mathrm{mg} / \mathrm{kg} \text { b.w })\end{array}$ & $108.52 \pm 8.26^{d}$ & $95.51 \pm 7.27 \mathrm{~d}$ & $72.81 \pm 5.54 \mathrm{~d}$ & $97.61 \pm 7.43 \mathrm{~d}$ \\
\hline
\end{tabular}

Values are expressed as mean \pm SD for six rats. Values not sharing a common superscript (a-d) differ significantly at $\mathrm{P}<0.05$ (DMRT)

\subsection{Effect of isopulegol on lipid profile in hepatic tissue}

The levels of TC, FFA, PL and TG in hepatic tissue of control and experimental rats were shown in Table 2. Diabetic rats exhibited a significant increase in the lipid content compared to normal rats. Administration of isopulegol to diabetic rats significantly reversed the lipid content in hepatic tissue to near normal.

Table 2: Effect of isopulegol on the levels of TC, TGs, FFAs and PLs in the hepatic tissue of normal and experimental rats

\begin{tabular}{lcccc}
\hline \multicolumn{1}{c}{ Groups } & TC (mg/dl) & TGs (mg/dl) & FFAs (mg/dl) & PLs (mg/dl) \\
\hline Normal & $5.60 \pm 0.42^{\mathrm{a}}$ & $4.05 \pm 0.30^{\mathrm{a}}$ & $18.05 \pm 1.37^{\mathrm{a}}$ & $21.50 \pm 1.63^{\mathrm{a}}$ \\
Normal+ isopulegol (200mg/kg b.w) & $5.30 \pm 0.40^{\mathrm{a}}$ & $4.10 \pm 0.31^{\mathrm{a}}$ & $17.04 \pm 1.30^{\mathrm{a}}$ & $20.62 \pm 1.57^{\mathrm{a}}$ \\
Diabetic (HFD/STZ) & $9.80 \pm 0.74^{\mathrm{b}}$ & $7.90 \pm 0.60^{\mathrm{b}}$ & $30.91 \pm 2.36^{\mathrm{b}}$ & $38.82 \pm 2.96^{\mathrm{b}}$ \\
Diabetic+ isopulegol (100mg/kg b.w) & $7.70 \pm 0.58^{\mathrm{c}}$ & $6.70 \pm 0.51^{\mathrm{c}}$ & $22.81 \pm 1.74^{\mathrm{c}}$ & $30.71 \pm 2.35^{\mathrm{c}}$ \\
Diabetic + metformin (25 mg/kg b.w) & $6.90 \pm 0.52^{\mathrm{d}}$ & $5.80 \pm 0.43^{\mathrm{d}}$ & $20.70 \pm 1.57^{\mathrm{d}}$ & $26.80 \pm 2.03^{\mathrm{d}}$
\end{tabular}

Values are expressed as mean \pm SD for six rats. Values not sharing a common superscript (a-d) differ significantly at P<0.05 (DMRT)

\subsection{Effect of isopulegol on lipoprotein cholesterol in plasma}

Table 3 depict the levels of lipoproteins cholesterol (HDL-C, LDL-C and VLDL-C) in the plasma of normal and experimental rats. The level of HDL-C was decreased whereas the levels of LDL-C and VLDL-C were significantly increased in diabetic rats when compared to normal control. Administration of isopulegol $(100 \mathrm{mg} / \mathrm{kg} \mathrm{b.w})$ decreased the levels of LDL-C, VLDL-C and significantly improved HDL-C levels in diabetic treated rats. The results are comparable with metformin $(25 \mathrm{mg} / \mathrm{kg}$ b.w) treated groups.

Table 3: Effect of isopulegol on the levels of HDL-C, LDL-C, VLDL-C in the plasma of normal and experimental rats

\begin{tabular}{lccc}
\hline \multicolumn{1}{c}{ Groups } & HDL-C (mg/dl) & LDL-C (mg/dl) & VLDL-C (mg/dl) \\
\hline Normal & $48.00 \pm 3.65^{\mathrm{a}}$ & $38.00 \pm 2.89^{\mathrm{a}}$ & $18.20 \pm 1.38^{\mathrm{a}}$ \\
Normal+ isopulegol (200mg/kg b.w) & $47.02 \pm 3.59^{\mathrm{a}}$ & $36.71 \pm 2.81^{\mathrm{a}}$ & $19.11 \pm 1.46^{\mathrm{a}}$ \\
Diabetic (HFD/STZ) & $24.61 \pm 1.88^{\mathrm{b}}$ & $90.24 \pm 6.91^{\mathrm{b}}$ & $32.51 \pm 2.48^{\mathrm{b}}$ \\
Diabetic+ isopulegol (100mg/kg b.w) & $34.61 \pm 2.64^{\mathrm{c}}$ & $50.92 \pm 3.89 \mathrm{c}$ & $25.61 \pm 1.95^{\mathrm{c}}$ \\
Diabetic + metformin (25 mg/kg b.w) & $40.50 \pm 3.08^{\mathrm{d}}$ & $43.70 \pm 3.32^{\mathrm{d}}$ & $21.80 \pm 1.65^{\mathrm{d}}$
\end{tabular}

Values are expressed as mean \pm SD for six rats. Values not sharing a common superscript (a-d) differ significantly at $\mathrm{P}<0.05$ (DMRT)

\subsection{Role of isopulegol on the activites of LPL and LCAT in plasma}

The activites of LCAT and LPL in plasma of normal control and experimental rats were shown in Table 4 . Decreased activites of LCAT and LPL were observed in the plasma of diabetic rats as compared to normal rats. Administration of isopulegol (100 mg/kg b.w) and metformin (25mg/kg b.w) to diabetic rats significantly increased the activites of LCAT and LPL towards near normal. 
Table 4: Effect of isopulegol on the activities of plasma LPL and LCAT of normal and experimental rats

\begin{tabular}{|c|c|c|}
\hline Groups & $\begin{array}{l}\text { LPL }(\mu \text { moles of glycerol } \\
\text { liberated } / \mathrm{h} / \mathrm{l})\end{array}$ & $\begin{array}{l}\text { LCAT }(\mu \text { moles of } \\
\text { cholesterol esterified } / \mathrm{h} / \mathrm{l})\end{array}$ \\
\hline Normal & $8.20 \pm 0.62$ a & $86.21 \pm 6.56^{\mathrm{a}}$ \\
\hline Normal+ isopulegol (200mg/kg b.w) & $7.30 \pm 0.55 \mathrm{a}$ & $87.39 \pm 6.68$ a \\
\hline Diabetic (HFD/STZ) & $4.50 \pm 0.34 b$ & $50.82 \pm 3.88^{b}$ \\
\hline Diabetic+ isopulegol (100mg/kg b.w) & $5.70 \pm 0.43^{c}$ & $65.73 \pm 5.03 c$ \\
\hline Diabetic + metformin $(25 \mathrm{mg} / \mathrm{kg} \mathrm{b.w})$ & $6.85 \pm 0.52 \mathrm{~d}$ & $75.91 \pm 5.77 \mathrm{~d}$ \\
\hline
\end{tabular}

Values are expressed as mean \pm SD for six rats. Values not sharing a common superscript (a-d) differ significantly at $\mathrm{P}<0.05$ (DMRT)

3.5 Effect of isopulegol on the activity of $\mathrm{HMG}-\mathrm{COA}$ reductase in hepatic tissue

Figure 1 shows the activity of HMG-COA reductase in control and experimental animals. The activity of HMG-COA reductase was increased significantly in hepatic tissue of diabetic rats. Oral administration of Isopulegol as well as metformin to diabetic rats significantly decreased the activity of HMG-COA reductase in these tissue when compared to diabetic control rats.

Figure 1: Effect of isopulegol on the activity of HMG-COA reductase in hepatic tissue of control and experimental rats

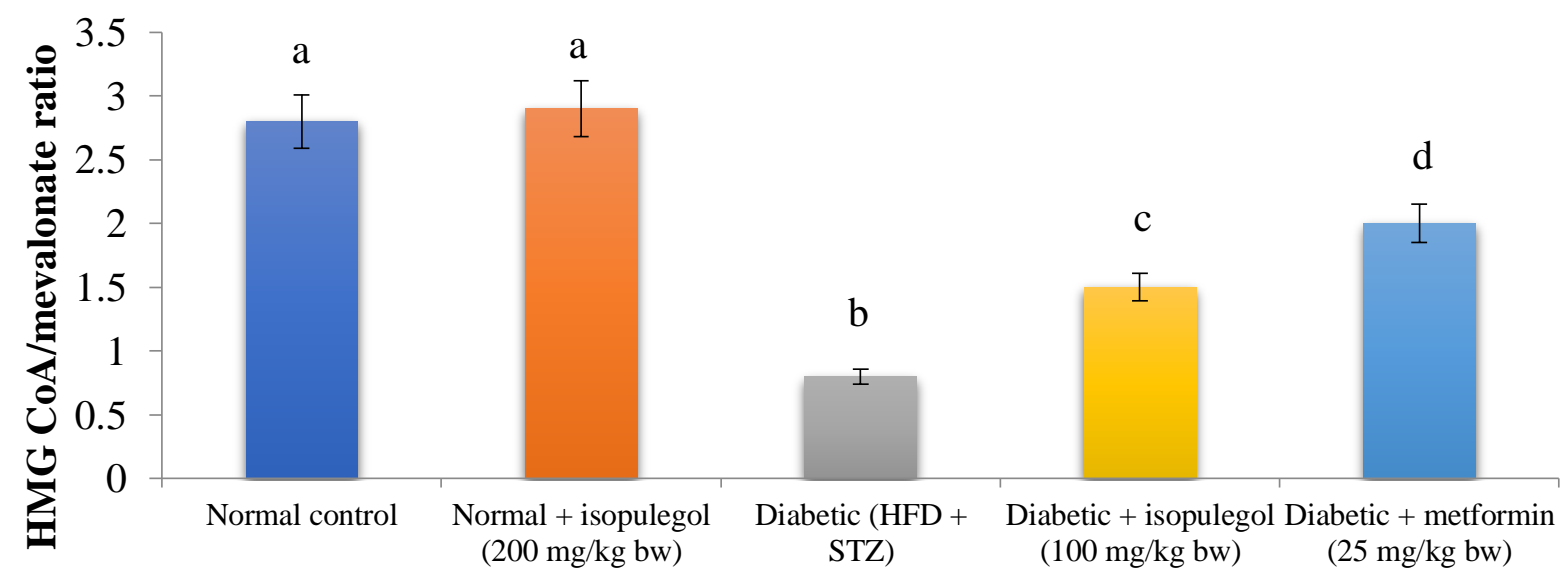

Groups

Values are expressed as mean \pm SD for six rats. Values not sharing a common superscript (a-d) differ significantly at $\mathrm{p}<0.05$ (DMRT).

\subsection{Role of isopulegol on the expression of adiponectin and leptin}

Figures 2 and 3 depicts the protein expression pattern of adiponectin and leptin in the adipose tissue of experimental rats. Significant downregulation of adiponectin with an upregulation of leptin expression was observed in diabetic control rats. Isopulegol $(100 \mathrm{mg} / \mathrm{kg}$ b.w $)$ treated diabetic rats significantly restored the protein expression pattern in the adipose tissue. 
Figure 2: Effect of isopulegol on adiponectin protein expression in the adipose tissue of normal and experimental rats A. Western blot analysis

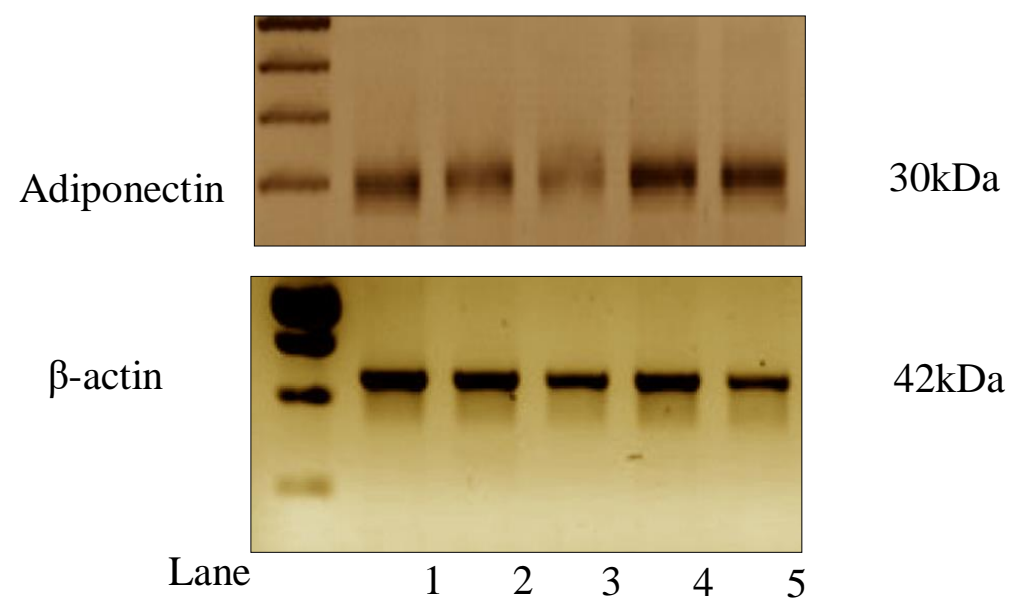

Lane 1: Normal; Lane 2: Normal+ isopulegol (200mg/kg b.w); Lane 3: Diabetic (HFD/STZ); Lane 4: Diabetic+ isopulegol (100mg/kg b.w); Lane 5: Diabetic + metformin (25 mg/kg b.w)

\section{B. Band intensity scanned by densitometer}

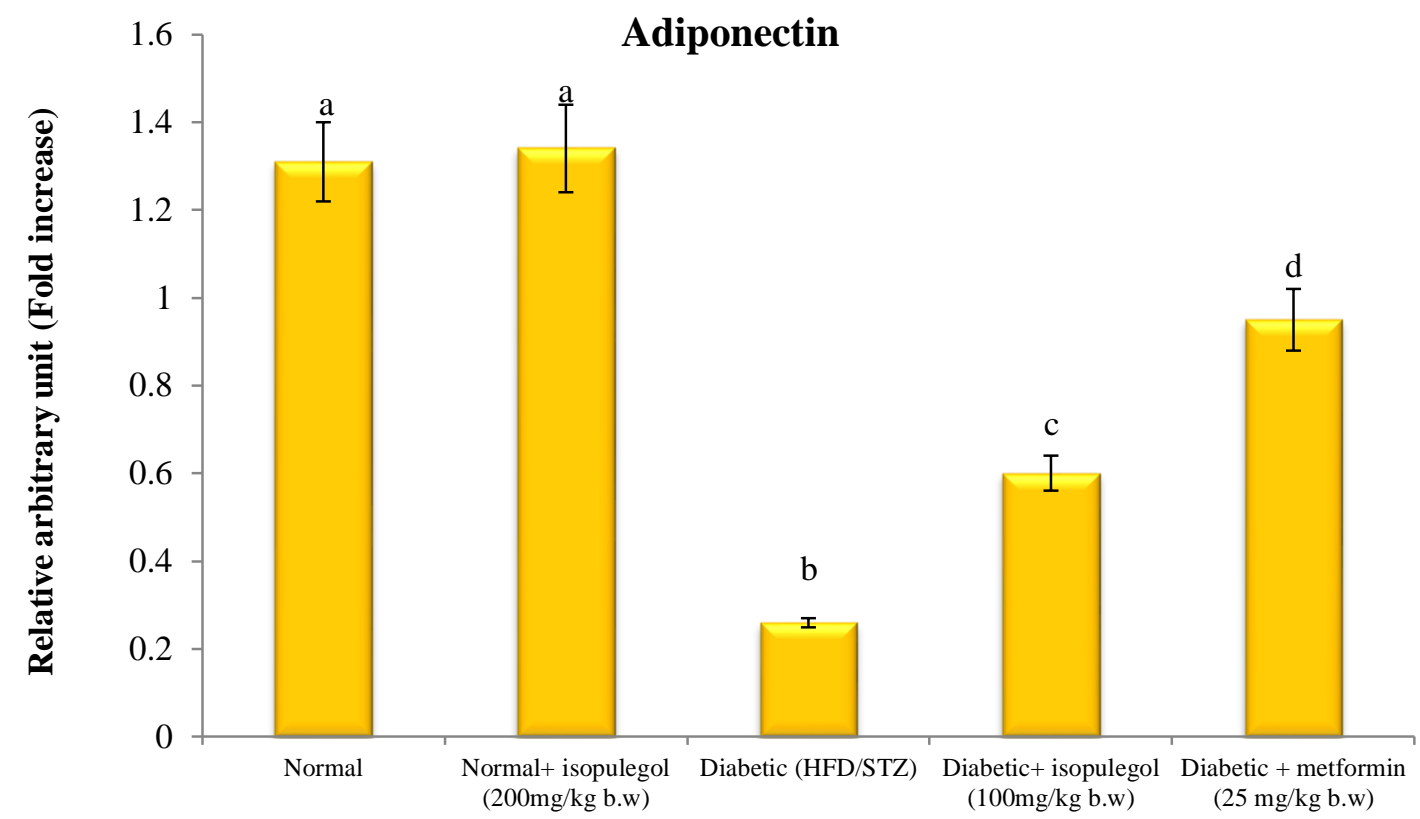

Histograms depicts quantization of three independent experiments (mean \pm S.D), with data normalized by defining the control group with adiponectin, as 1 unit. Values are not sharing a common superscript differ significantly at $p<0.05$ (DMRT) 
Figure 3: Effect of isopulegol on leptin protein expression in the adipose tissue of normal and experimental rats A. Western blot analysis

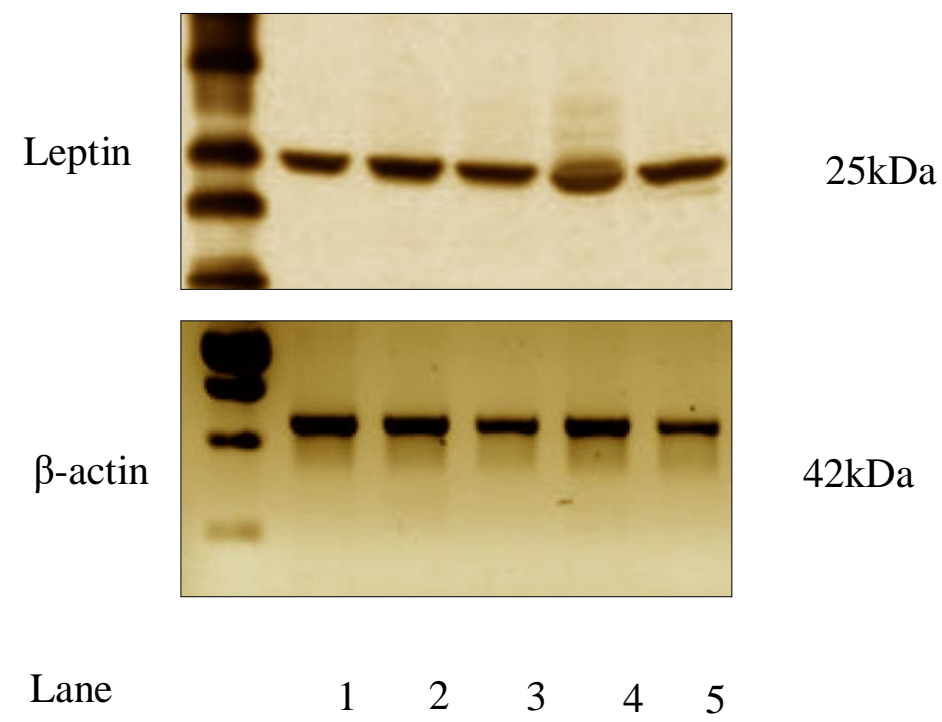

Lane 1: Normal; Lane 2: Normal+ isopulegol (200mg/kg b.w); Lane 3: Diabetic (HFD/STZ); Lane 4: Diabetic+ isopulegol (100mg/kg b.w); Lane 5: Diabetic + metformin (25 mg/kg b.w $)$

\section{B. Band intensity scanned by densitometer}

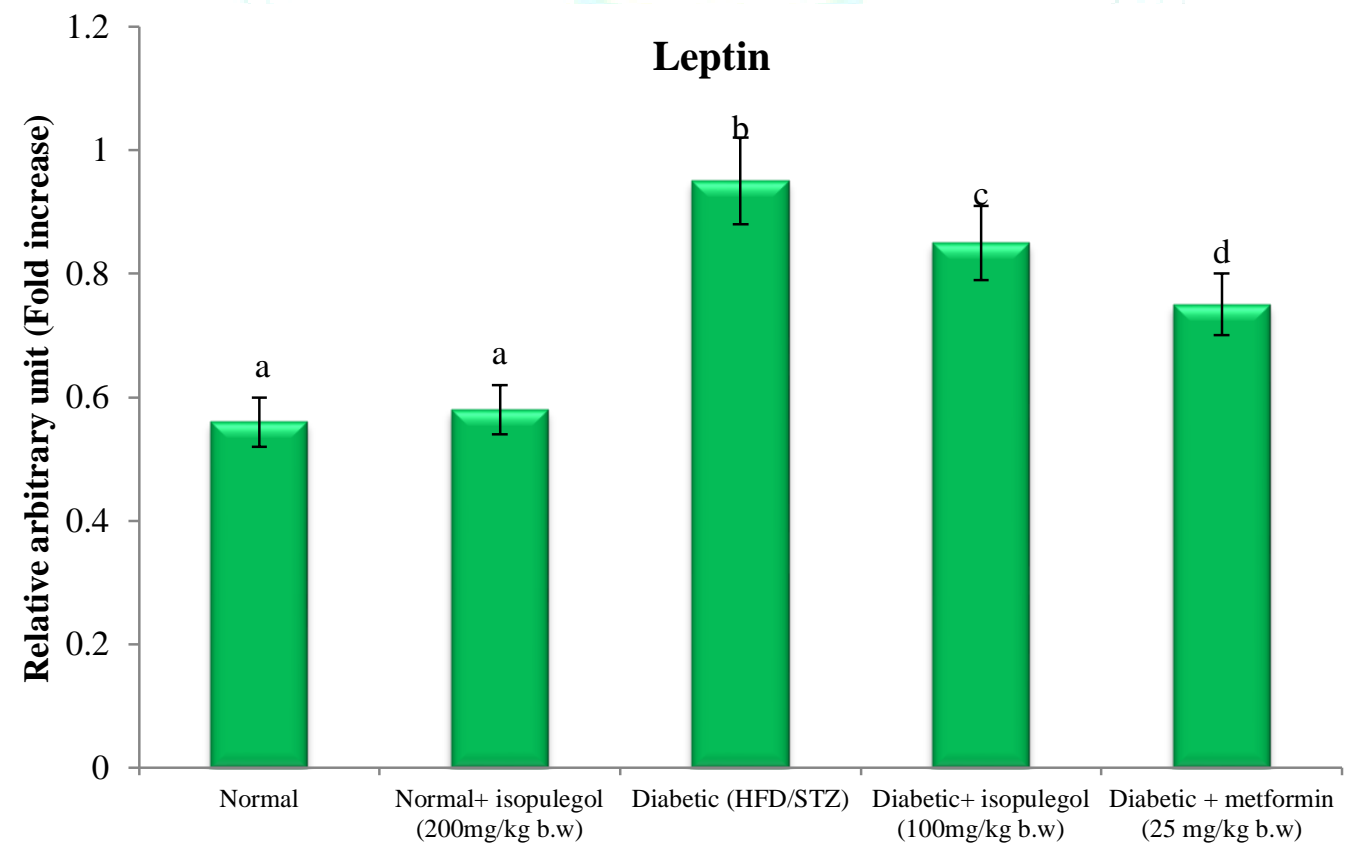

Histograms depicts quantization of three independent experiments (mean \pm S.D), with data normalized by defining the control group with adiponectin, as 1 unit. Values are not sharing a common superscript differ significantly at $p<0.05$ (DMRT)

\subsection{Effect of isopulegol on mRNA expression of PPAR $\gamma$ and SREBP-1C in diabetic rats}

The effect of isopulegol on the mRNA expression of PPAR $\gamma$ and SREBP-1C in the adipose tissue of diabetic rats are shown in (Figures 4 - 6). The levels of PPAR $\gamma$ mRNA expression was significantly down regulated whereas SREBP-1C mRNA expression were significantly up regulated in diabetic rats compared to control rats. Treatment with isopulegol $(100 \mathrm{mg} / \mathrm{kg}$ b.w) significantly modulated PPAR $\gamma$ and SREBP-1C mRNA expression to near normal in treated diabetic rats compared to metformin treated rats. 
Figure 4: Analysis of PPAR $\gamma$ expression by qRT-PCR in adipose tissue of experimental rats
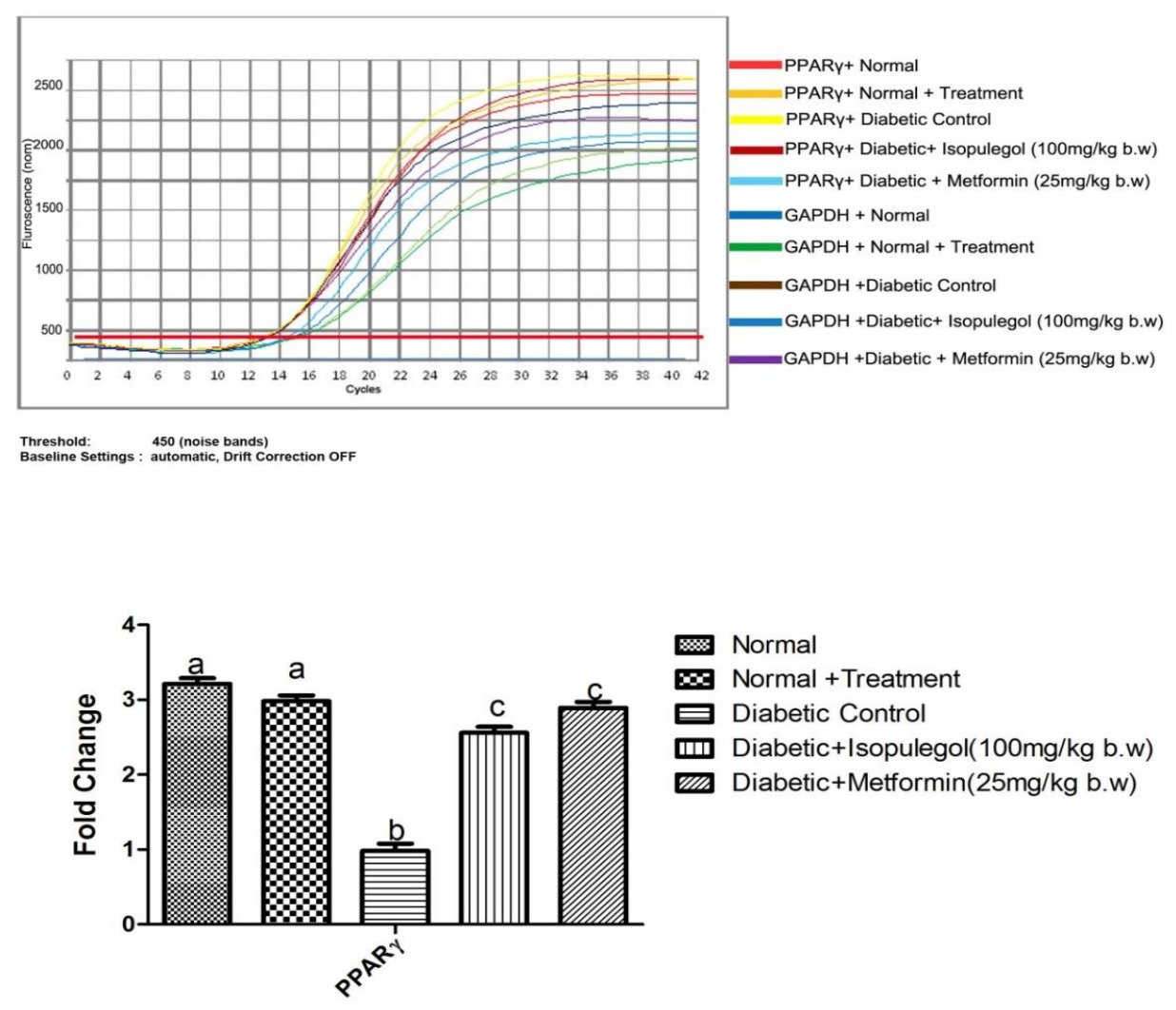

q-RT-PCR analysis graph. b) PPAR $\gamma$ mRNA expression by q-RT-PCR in adipose tissue. Experiments were carried out in triplicates and data expressed are mean \pm SD of 6rats from each group. The Ct values of the test gene of each group were standardized using Ct value of GAPDH of the same group. Values are expressed relative to those control rats that were arbitrarily assigned a value of 1.0 .

\section{Figure 5 : Analysis of SREBP-1C expression by qRT-PCR in adipose tissue of experimental rats}
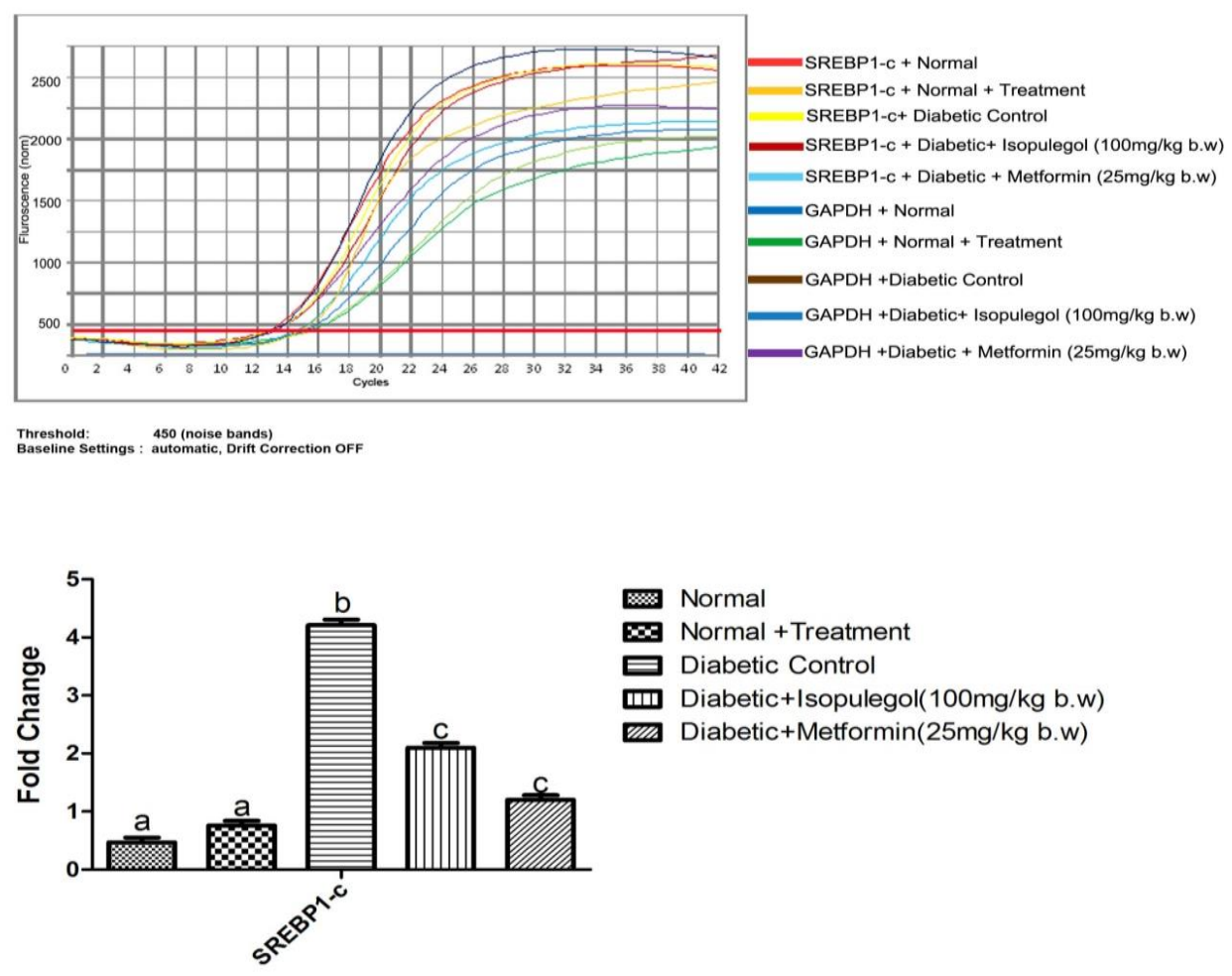

q-RT-PCR analysis graph. b) SREBP-1C mRNA expression by q-RT-PCR in adipose tissue. Experiments were carried out in triplicates and data expressed are mean \pm SD of 6rats from each group. The Ct values of the test gene of each group were 
standardized using $\mathrm{Ct}$ value of GAPDH of the same group. Values are expressed relative to those control rats that were arbitrarily assigned a value of 1.0 .

Figure 6: Analysis of SREBP-1C expression by qRT-PCR in the liver of experimental rats

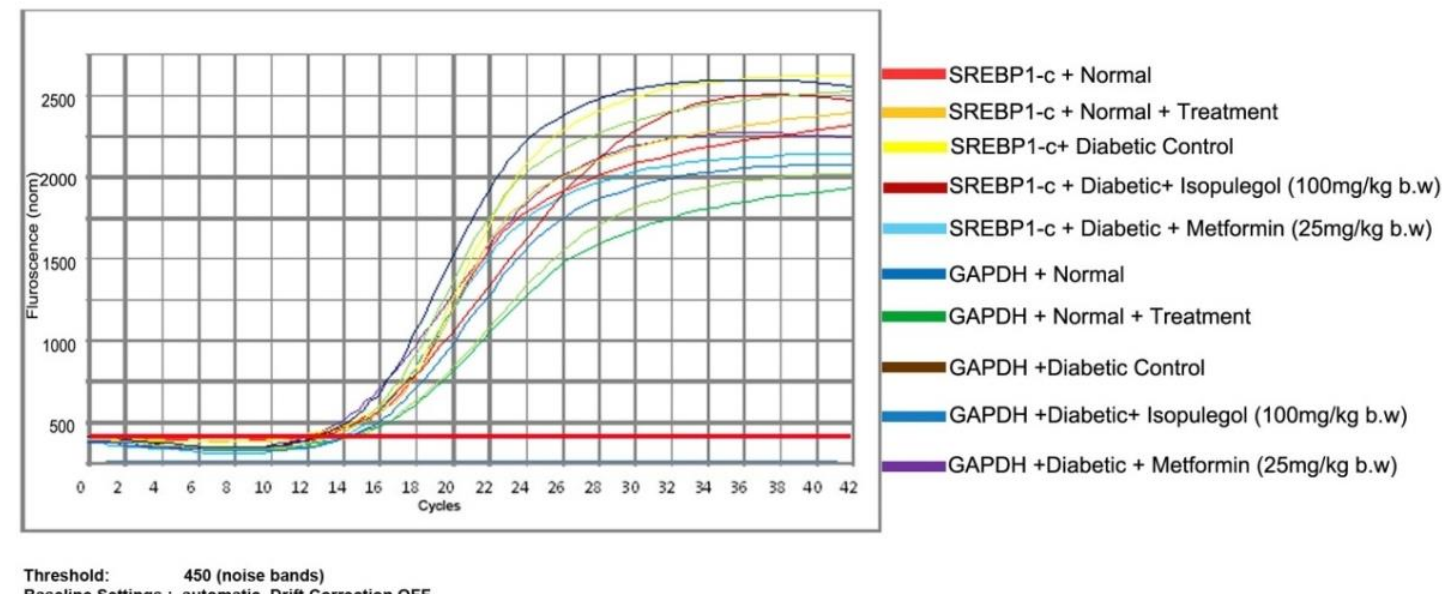

$\begin{array}{ll}\text { Threshold: } & 450 \text { (noise bands) } \\ \text { Baseline Settings : automatic, Drift Correction OFF } & \end{array}$
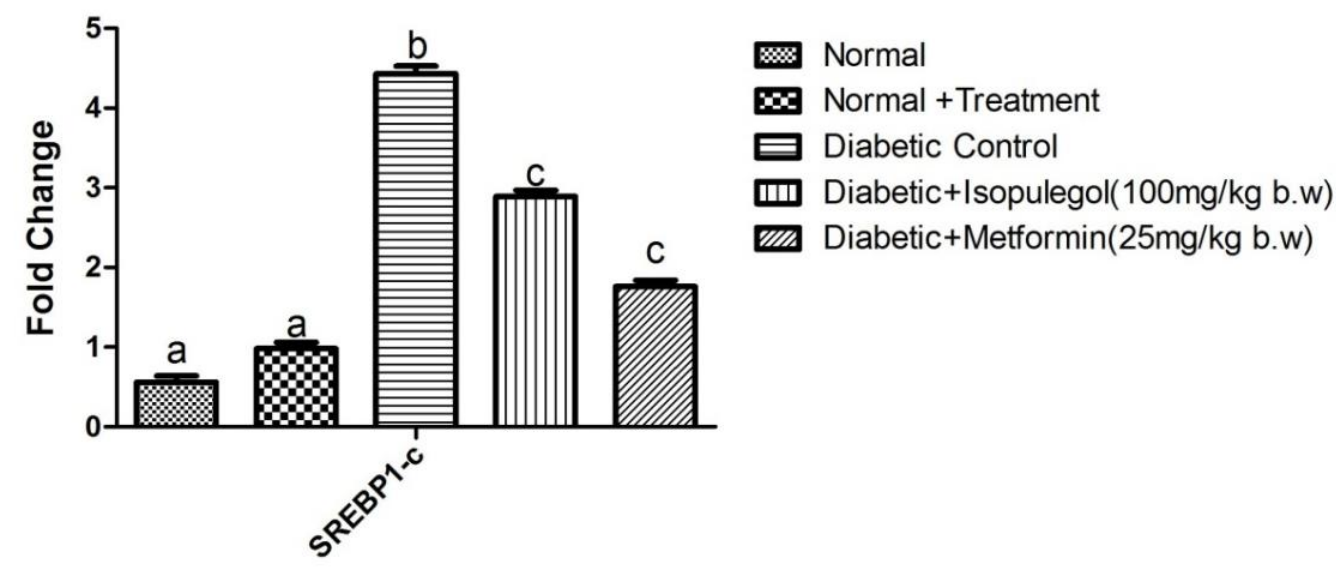

q-RT-PCR analysis graph. b) SREBP1-C mRNA expression by q-RT-PCR in liver tissue. Experiments were carried out in triplicates and data expressed are mean \pm SD of 6rats from each group. The $\mathrm{Ct}$ values of the test gene of each group were standardized using $\mathrm{Ct}$ value of GAPDH of the same group. Values are expressed relative to those control rats that were arbitrarily assigned a value of 1.0 .

\subsection{Histology}

Histological observations of haematoxylin-eosin-stained adipose tissue of control and treated rats are shown in (Figure.7). Diabetic rats showed swollen arrangement of cells in the epididymal adipose tissue. Oral administration of isopulegol $(100 \mathrm{mg} / \mathrm{kg} \mathrm{b.w})$ restored the architecture of adipose tissue to near normal. 
Figure 7: Histopathological changes in adipose tissue of normal and experimental rats

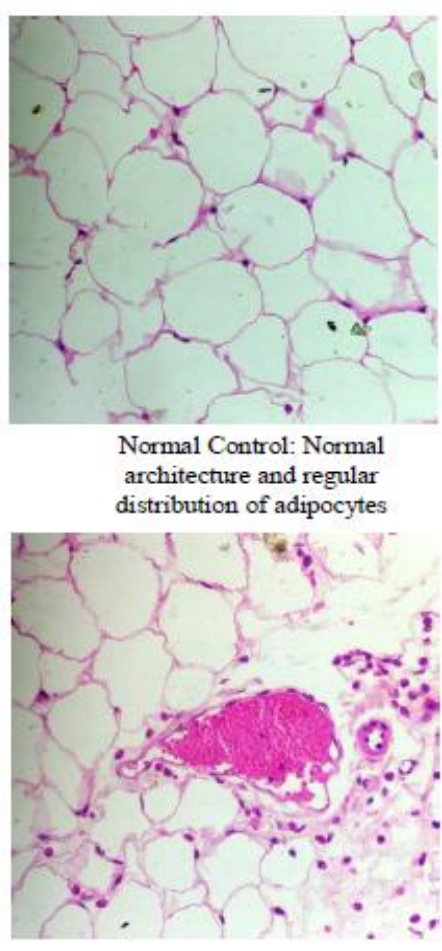

Diabetic control : Hypertrophy of adipocytes and infiltration of macrophages

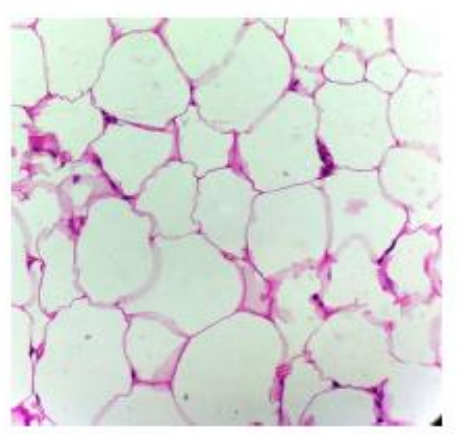

Normal + Isopulegol: Normal architecture and regular disturbution of adipocytes

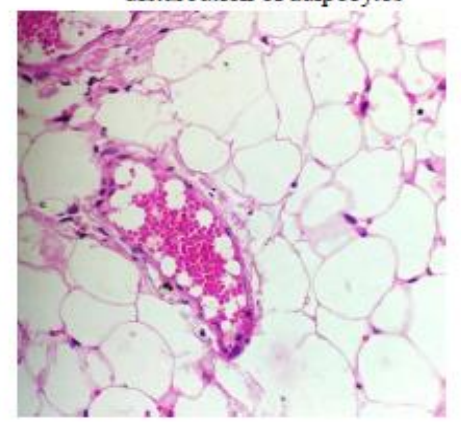

Diabetic + Isopulegol: Mild inflammation of adipocytes

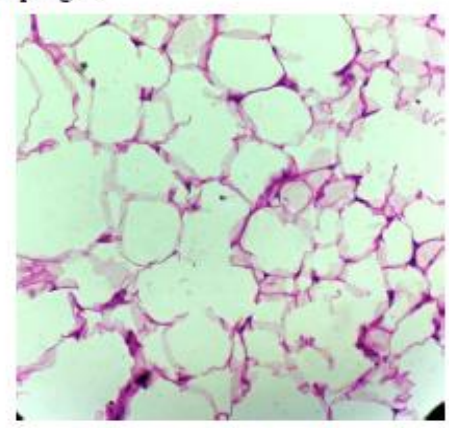

Diabetic + Metformin: Normal and regular distribution of adipocytes

\section{DISCUSSION}

Increasing availability of energy dense food and sedentary lifestyle have led to a worldwide epidemic of type 2 diabetes mellitus. Dyslipidemia is a common biochemical feature in T2DM and is one of the major risk factors for cardiovascular and peripheral vascular disease (CVD) [15]. Insulin deficiency/resistance contributes to quantitative and qualitative lipid abnormalities with a shift towards atherogenic lipid profile that result in microvascular and macrovascular disorders.

Free fatty acids are products of fat metabolism in adipose tissues and it is the main circulating lipid fuel in the postabsorptive state. The mobilization of free fatty acids from stored TG occurs sequentially and requires the activation of hormone sensitive lipase (HSL), a key enzyme considered as crucial in regulating lipolysis in fat cells [16]. This enzyme is under tight hormonal and neuronal control and it has been found that variations in HSL expression modulate lipolysis in adipose tissue. In the diabetic state, insulin deficiency causes activation of HSL that results in hydrolysis of TG with concomitant release of large amounts of free fatty acids in circulation.

Hypertriglyceridemia is a common finding in diabetic patients and is responsible for vascular complications. Lipid accumulation in hepatic tissue is mediated through a variety of derangements in metabolic and regulatory processes leading to hypercholesterolemia and hypertriglyceridemia [17].In the diabetic state, insulin deficiency increases mobilization of fatty acids from adipose tissue which are channelized to liver and esterified resulting in hypertriglyceridemia [18].

Furthermore, lipoprotein lipase (LPL) catalyses the hydrolysis of the triglyceride component of chylomicrons, VLDL and provides non-esterified fatty acids and 2- 
monoacylglycerol for tissue utilisation. In diabetes mellitus, due to insulin deficiency the expression and activity of LPL is decreased resulting in impaired metabolism of TG rich lipoproteins leading to hypertriglyceridemia. We observed an increase in FFA, TG and LPL activity in HFD/STZ diabetic rats.

Sterol regulatory element (SREBPs) transcription factor regulate the expression of lipogenic genes, such as fatty acid synthase and acetyl-CoA carboxylase, involved in lipid biosynthesis and uptake [19]. Studies have shown that increased expression of SREBP-1C accelerate TG accumulation in diabetic rats [20]. We observed an upregulation in the mRNA expression of SREBP-1C in the hepatic and adipose tissue of diabetic rats.

Cholesterol homeostasis is an important metabolic process which reflects a balance between numbers of complex/ interactive processes. The biosynthesis of cholesterol is regulated by the rate-limiting enzyme HMG-CoA reductase, which catalyzes production of mevalonic acid. Increased activity of HMG-CoA reductase results in the excessive production and accumulation of cholesterol leading to the formation of foam cells, a pre-requisite step in the development of atherosclerosis [21]. Insulin deficiency is associated with decreased HMG $\mathrm{CoA} /$ mevalonate ratio indicating increased enzyme activity. Numerous studies have highlighted that the activity of HMG-CoA reductase is increased in diabetic rats [22].

Phospholipids are vital components of bio membranes that play an important role in the maintenance of cellular integrity, micro viscosity and survival. An elevation of FFA and cholesterol in diabetic rats, promote the synthesis of PLs [23]. PLs are susceptible substrates for oxygen and hydroxyl free radicals generated in diabetic state. In DM, chronic hyperglycemia alters fatty acids, lipids and decreases the activities of membrane-bound enzymes [24].We observed an increase in cholesterol, phospholipids and HMG CoA reductase activity in plasma and liver tissue of diabetic rats.

In the present study, treatment with isopulegol $(100 \mathrm{mg} / \mathrm{kg}$ b.w) for 28 days was sufficient to produce a significant decrease in the levels of FFA, TC, TG, PL and in the mRNA expression of SREBP-1C in diabetic treated rats. Similarly, the observed increase in HMG-COA reductase and a decrease in LPL activity were restored to near normal in isopulegol treated diabetic rats. These results indicate that isopulegol has significant lipid lowering effect in diabetic treated rats. Our findings are in line with wang et al who reported that Inonotus obliques polysaccharides normalized lipid profile in streptozocin diabetic rats [25].

In diabetic state, alterations in lipoprotein patterns are accompanied by changes in variety of biochemical processes. The transport of TG from liver to extrahepatic tissues for utilization and storage is achieved by VLDL [26]. Increased free fatty acid flux from lipolysis under insulin resistant conditions results in excessive production of VLDLs in the liver. These particles are synthesized in the liver and contain apo B-100 as their apolipoprotein component. Insulin deficiency increases the flux of metabolites to liver leading to overproduction of VLDL and also enhances its secretion through regulating the turnover apoB100 [27]. This process is severely impaired in diabetes mellitus resulting in increased VLDL-C in circulation.

LDL cholesterol (LDL-C) is central importance in evaluating the effects of lipid modifying therapies. The atherogenic properties of LDL particles are related to their ability to penetrate the arterial wall and make them susceptible to oxidation. Increased LDL-C may arise on glycosylation of the lysyl residue of apoprotein- B as well as from decreasing affinity for the LDL receptor. These modifications results in decreased clearance of LDL particles by LDL-receptor (LDLR) and contribute to their elevated plasma levels [28]. A positive correlation exists between the incidence of coronary atherosclerosis and the oxidative modification of LDL particles.

HDL promotes the reverse transport of cholesterol from peripheral tissues to liver with the help of ABCA1 transporter protein. The anti-atherogenic effect of HDL is due to its antioxidant/anti-inflammatory function, which is of great significance in DM . The antioxidant effect is related to the presence of HDL-linked proteins (apo-A1, lecithin: cholesterol acyltransferase (LCAT), platelet-activating factor acetyl hydrolase) and paraoxonase (PON). HDL also acts as a repository of apolipoproteins $\mathrm{C}$ and $\mathrm{E}$ and governs the metabolism of chylomicrons and VLDL. Apo A1, the major apo protein of HDL-C is glycated in uncontrolled diabetes and results in increased permission of HDL particles from circulation [29]. LCAT a key enzyme in HDL-C metabolism facilitates the transfer of a fatty acid from position 2 of lecithin to cholesterol to form cholesteryl esters. This allows the transfer of cholesteryl ester to the core of HDL particle rendering the continuous uptake of free cholesterol by HDL. A decrease in LCAT activity severely impairs HDL-C synthesis and TGs metabolism in diabetic rats [30].

We observed a significant increase in VLDL-C and LDL-C levels with a decrease in HDL-C level in the plasma of diabetic rats. A decreased activity of LCAT was observed in plasma of diabetic rats. Treatment with isopulegol (100mg/kg b.w) improved lipoprotein cholesterol levels and LCAT activity in diabetic treated rats. The hypolipidemic effect of isopulegol is attributed to a significant reduction in blood glucose concentration via enhanced insulin secretion. This enhancement in insulin, increase utilization of glucose and decreases the mobilization of FFA from fat depots. Our results are consistent with Antony et al (2016) who reported that myoinositol improved lipoprotein cholesterol levels and LCAT activity in HFD/STZ diabetic rats.

Adiponectin, improves insulin sensitivity and regulates energy homeostasis. It has been shown that adiponectin activates AMP-activated protein kinase (AMPK) and reduces the expression of gluconeogenic genes and enhances insulin sensitivity both in skeletal muscle and liver [31]. It is suggested that adiponectin plays an important role in lipid metabolism by stimulating fatty acid oxidation in liver and muscle, decreases plasma triglycerides and enhances glucose metabolism. High-fat diet and STZ induced diabetes was accompanied by a reduction in plasma adiponectin levels [32].

Leptin, decreases food intake, body weight and modulates glucoses and fat metabolism. It targets pancreatic $\beta$-cell, modulates insulin expression and secretion[33]. It also influences lipid metabolism by preventing TG accumulation in peripheral tissues. It has been found out that leptin stimulates fatty acid oxidation through AMP-activated protein kinase (AMPK) and subsequently inhibits acetyl-CoA carboxylase (ACC) activity in the skeletal muscle [34]. Increased circulating levels of leptin have been found to be associated with obesity and in chronic consumption of highfat diet. Studies have reported that circulating levels of both leptin and lipids are increased on high fat feeding in C57BL/6J mice [35].

Our study revealed a significant down regulation in the expression of PPAR $\gamma$, adiponectin and an upregulation of leptin expression in the adipose tissue of diabetic rats. Histopathological studies of revealed hypertrophy and 
infiltration of macrophages in adipose tissue suggesting profound dysfunction in HFD/STZ diabetic rats. Administration of isopulegol and metformin to diabetic rats markedly restored changes in the expression levels of PPAR $\gamma$, adiponectin and leptin in adipose tissue. The possible mechanism of isopulegol in the improvement of adipokines may be due to the activation of PPAR $\gamma$ in the adipose tissue. Our findings are in agreement with Hosni et al the reported that cinnamaldehyde effectively improved insulin secretion and sensitivity by up regulation of PPAR $\gamma$ gene expression and diminishing the proinflammatory cytokines in diabetic rats [36]

\section{CONCLUSION}

From this we conclude that administration of isopulegol effectively regulated adipokine expression, restored the levels of lipids and lipoprotein cholesterol by regulating the activities of key enzymes and ameliorated dyslipidemia in diabetic rats. In addition, histopathological studies revealed a protective effect of isopulegol. Further studies are warranted to unravel the molecular action of isopulegol in controlling dyslipidemia in diabetes mellitus.

\section{ACKNOWLEDGEMENT}

The authors gratefully thank UGC and DST, New Delhi for their financial support to the department.

\section{CONFLICT OF INTEREST}

The authors have no conflict of interest to declare.

\section{REFERENCES}

[1] Tangvarasittichai $S$, Oxidative stress, insulin resistance, dyslipidemia and type 2 diabetes mellitus, World J Diabetes, 2015; 6: 456-480.

[2] Hussain AI, Seasonal variation in content, chemical composition and antimicrobial and cytotoxic activities of essential oils from four Mentha species, J Sci Food Agric, 2010; 90: 1827-1836.

[3] Kalaivani K and Sankaranaryanan C, Modulatory effect of isopulegol on hepatic key enzymes of glucose metabolism in high fat diet/streptozotocin induced diabetic rats, Archives of physiology and biochemistry, 2019; 10:1-9.

[4] Folch J, Lees M, and Solane SGH. A simple method for isolation and purification of total lipids from animal tissues, J. Biol. Chem, 1957;26: 497-509.

[5] McGowan MW, A peroxidase-coupled method for the colourimetric determination of serum triglycerides, Clin.Chem, 1983; 29: 538-542.

[6] Falholt K, Falholt W and Lund B , An easy colourimetric routine determination of free fatty acids in plasma, Clin Chim Act, 1973;46:105-111.

[7] Zilversmit DB, Davis AK, Micro determination of phospholipids by TCA precipitation, J Lab Clin Med, 1950.;35: $159-161$.

[8] Izzo C, Grillo F, Murador E, Improved method for determination of high-densitylipoprotein cholesterol I. Isolation of high-density lipoproteins by use of polyethylene glycol 6000, Clin Chem, 1981; 27: 371-374.

[9] Friedwald WT, Levy RJ, Fredricken DS, Estimation of HDL-C in the plasma without the use of preparative ultracentrifuge,Clin. Chem, 1972;18: 449.

[10] Korn ED, Clearing factor: a heparin activated lipoprotein lipase: isolation and characterization of enzyme from normal rats, J. Biol. Chem, 1955;215: 1-26.

[11] Hitz J, Steinmetz J, Siest G, Plasma lecithin: cholesterol acyltransferasereference values and effects of xenobiotics, Clin. Chim. Acta, 1983; 133: 85-96.

[12] Zlatkis A, Zak B, Boyle AJ, A new method for the direct determination of serum cholesterol, J Lab Clin Med, 1953;41:486-492.

[13] Laemmli UK. Cleavage of structural proteins during the assembly of the headof bacteriophage T4. Nature, $1970 ; 227$ 680-685.
[14] Hine IF, Block staining of mammalian tissues with hematoxylin and eosin, Stain Technol, 1981;56: 119-123.

[15] Chen SC and Tseng CH, Dyslipidemia, kidney disease, and cardiovascular disease in diabetic patients, Rev Diabet Stud, 2013;10:88-100.

[16] Leon BM and Maddox TM, Diabetes and cardiovascular disease: Epidemiology, biological mechanisms, treatment recommendations and future research, World J Diabetes, 2015; 6 : 1246-1258.

[17] Plaisance EP and Fisher GI, Exercise and dietary-mediated reductions in postprandial lipemia, J Nutr Metab, 2014;90:2065.

[18] Suzuki T, Sawada S, Ishigaki Y, Lipoprotein Lipase Deficiency (R243H) in a Type 2 Diabetes Patient with Multiple Arterial Aneurysms, Intern Med, 2016;55:1131-1136.

[19] Shimano H, SREBP-1c and Elovl6 as Targets for Obesityrelated Disorders, Yakugaku Zasshi, 2015; 135 : 1003-1009.

[20] Desert C., et al., Multi-tissue transcriptomic study reveals the main role of liver in the chicken adaptive response to a switch in dietary energy source through the transcriptional regulation of lipogenesis. BMC Genomics, 2018;19:187.

[21] Tsoupras A, Lordan R and Zabetakis, I Inflammation, not Cholesterol, Is a Cause of Chronic Disease, Nutrients, 2018;10:12.

[22] Jiang $\mathrm{H}$., et al., Discovery of a potent HMG-CoA reductase degrader that eliminates statin-induced reductase accumulation and lowers cholesterol, Nat Commun, 2018; 9 :5138.

[23] Dawaliby R, Trubbia C and Delporte C. Phosphatidyl ethanolamine Is a Key Regulator of Membrane Fluidity in Eukaryotic Cells, J Biol Chem, 2016;291: 3658-3667.

[24] Russell J., et al., Myocyte membrane and microdomain modifications in diabetes: determinants of ischemic tolerance and cardioprotection, Cardiovasc Diabetol, 2017;16:155.

[25] Wang J., et al., Anti-diabetic effects of Inonotus obliquus polysaccharides in streptozotocin-induced type 2 diabetic mice and potential mechanism via PI3K-Akt signal pathway. Biomed Pharmacother, 2017;95:1669-1677.

[26] Wassef H., et al., Enrichment of Triglyceride-Rich Lipoproteins with Apolipoprotein C-I Is Positively Associated with Their Delayed Plasma Clearance Independently of Other Transferable Apolipoproteins in Postmenopausal Overweight and Obese Women, J Nutr, 2017;147:754-762.

[27] White CR, Garber DW and Anantharamaiah GM, Antiinflammatory and cholesterol-reducing properties of apolipoprotein mimetics: a review, J Lipid Res, 2014 ; 55:2007- 2021.

[28] Ganjifrockwala F, Joseph J, George G, Serum Oxidized LDL Levels in Type 2 Diabetic Patients with Retinopathy in Mthatha Region of the Eastern Cape Province of South Africa. Oxid Med Cell Longev, 2016; 20: 103.

[29] Femlak M., et al., The role and function of HDL in patients with diabetes mellitus and the related cardiovascular risk. Lipids Health Dis, 2017;16:207.

[30] Antony PJ and Gandhi GR, Myoinositol ameliorates high-fat diet and streptozotocin-induced diabetes in rats through promoting insulin receptor signaling. Biomed Pharmacother, 2017; 88: 1098-1113.

[31] Iwabu M., et al., Adiponectin/ adiponectin receptor in disease and aging. NPJ Aging Mech Dis, 2015;1: 150-213.

[32] Ahmed Eissaa L., et al., Omar Maghmomeha. Effect of 2hydroxychalcone on adiponectin level in type 2 diabetes induced experimentally in rats. Egyptian journal of Basic and applied sciences, 2017; 4: 8.

[33] Perry B and Wang Y, Appetite regulation and weight control: the role of gut hormones. Nutr Diabetes, 2012; 2:26.

[34] Yoon MJ., et al., Adiponectin increases fatty acid oxidation in skeletal muscle cells by sequential activation of AMPactivated protein kinase, p38 mitogen-activated protein kinase, and peroxisome proliferator-activated receptor alpha. Diabetes, 2006;55: 2562-2570.

[35] Moon HS., et al., Leptin's role in lipodystrophic and nonlipodystrophic insulin-resistant and diabetic individuals. Endocr Rev, 2013; 34: 377-412.

[36] Hosni AA., et al., A.A, Cinnamaldehyde potentially attenuates gestational hyperglycemia in rats through modulation of PPAR $\gamma$, proinflammatory cytokines and oxidative stress. Biomed Pharmacother, 2017; 88: 52-60. 
